\title{
New wind for the Spanish Federation of Scientific Oncological Societies (FESEO)
}

\author{
S. González-Moreno ${ }^{1}$ (i) on behalf of the FESEO Board of Directors
}

Published online: 6 June 2018

(๐) Federación de Sociedades Españolas de Oncología (FESEO) 2018

\section{By principle, Oncology is multidisciplinary}

The cancer cell needs the conjunction of different molecular and genetic events just to exist and more so to progress into a detectable and threatening disease. At the clinical level, the diagnosis and therapeutic management of cancer is a mirror image of the complexity and diversity of the disease at the biological level. Targeting only one of the various elements involved in cancer inception and promotion, even when it could leave us with a false sense of transient success, is not enough to eradicate the disease. Likewise, only the conjunction and fine coordination of clinical cancer specialists, all of them with a common and solid scientific knowledge on cancer, while each one of them an expert in a field within the varied and growing cancer therapy armamentarium, will provide the best management plan that can bring hope to a cancer patient. Other clinical specialists, expert pathologists and diagnostic imaging colleagues show us the target. Continued efforts and successes in basic and translational research guide our work and provide new clues towards our common final goal and hope: to beat cancer.

Every cancer patient deserves that his or her case is discussed at a multidisciplinary conference where all the specialists involved in his/her cancer diagnosis and management are present. Before this conference takes place, a true commitment amongst all participants not to take any diagnostic or therapeutic irreversible decisions is implicitly and/or explicitly made. At the end, a clear individualized diagnostic and clinical care road map is produced, annotated in the patient's chart and subsequently conveyed to the patient.

FESEO Board of Directors are listed in Acknowledgement section.

S. González-Moreno

sgonzalezm@mdanderson.es

1 MD Anderson Cancer Center, Calle Arturo Soria, 270, 28033 Madrid, Spain

\section{Multidisciplinary Oncology in Europe}

Real multidisciplinarity in the context of the leading scientific oncological societies in Europe is severely threatened these days. The European CanCer Organization (ECCO), composed of most scientific and patient-advocate organizations dealing with cancer in Europe, is undergoing the most severe crisis since it was originally founded as FECS (Federation of European Cancer Societies), close to facing disappearance. In a difficult-to-understand movement from the scientific and clinical standpoints, the powerful European Society for Medical Oncology (ESMO) decided to leave ECCO, dragging the European Association for Cancer Research (EACR) with her. It is actually interesting to observe how the ESMO membership either ignores or is flabbergasted by and against this "purely political" movement that cracks any possibility of a true multidisciplinary common voice for cancer in Europe.

The once biannual and very successful ECCO-ESMO Congress with thousands of delegates has been scaled down to a much smaller but genuine Oncopolicy forum co-led by cancer patient organizations and all cancer-related scientific societies except for ESMO and EACR, called "ECCO Summit", that will take place in Vienna, Austria on September $7-9,2018$. The ultimate goal is to be able to have an influence in European cancer policy through the European Parliament and other gateways.

Tireless continued conversations are warranted in order to pave the way for a true multidisciplinary forum in Europe where we all can fit, if we want to use the word "multidisciplinary" in this context adequately in the future. The titanic efforts in this direction of Peter Naredi as Past President and Philip Poortans ad current President of ECCO do not go unnoticed. 


\section{Multidisciplinary Oncology in Spain}

FESEO was created as such in 1987 as a forum to represent and foster multidisciplinarity in the Spanish Oncology landscape. It is a Federation of the leading Spanish scientific societies involved in cancer care and research at all levels.

As Oncology has grown more and more complex, the related pharma industries have transformed and economic crises set in, our member scientific societies evolved to adapt to new demands that on occasion had threatened their sustainability.

As their umbrella, FESEO has not been oblivious to this fact. Its economic viability was clearly threatened and its ability to lead and propose true multidisciplinary initiatives was severely diminished. There were occasions when it was not clear whether all member societies still shared a common vision and it was not strange to hear voices calling for the end of FESEO, in the belief that each or some societies on their own would do better.

It is fair to say that since its creation and through this crisis in sustainability and in a shared vision, Clinical and Translational Oncology (CTO), FESEO's organ of expression as well as that of its member societies has remained as the glue that, for one reason or another, has kept us all together and has allowed FESEO to survive. And this is the only fact that matters now. Nobody that knows this reality will deny that without CTO, FESEO would not exist today.

At this point, it needs to be acknowledged and mentioned that a significant contribution in this direction is to be attributed to the work done over the years by our past Editor-inChief, J. C. Lacal and by the current one Pere Gascón. It is also fair to acknowledge FESEO Past Presidents under whose solid and remarkable leadership, in very unfavorable conditions, spent significant efforts and personal time to lead the Federation through the recent crisis that threatened its very existence. These are Juan Jesús Cruz (SEOM, FESEO President 2013-2015), and Alfredo Carrato (ASEICA, FESEO President 2015-2017), from whose hands the current Board of Directors inherited a revamped, economically recovered and revitalized FESEO with a strong editorial team and editorial policy renovation for CTO, resulting in a rising star in the international Oncology publishing world. We cannot omit our publisher Springer, always sensitive to our needs, always open to negotiate, which has resulted in a very attractive online-only journal, granting us additional and creative chances to balance our accounts and create revenues in a new era when resources from the pharma industry are not as readily available as in the past, due to the lack of advertisement opportunities in the online only format. Springer has certainly been and remains a true partner for us.

Taking into account all the above, in an era when multidisciplinarity in Oncology should be a reality with all its consequences (and not just a mere word whose meaning is becoming blurred by its often inadequate use) and with the common pride shared by all that FESEO has made it until today, member societies are willing to write a new chapter in its history, so that FESEO carries forward its genuine mission and vision, with renewed enthusiasm and motivation.

As mentioned, CTO remains our best asset. It does boast very good health, with the latest published Impact Factor of 2.353, 837 manuscripts received in 2017 and a $73 \%$ rejection rate that same year. Its reach is worldwide and its economic sustainability is a reality. Building on these foundations, we all are willing to explore further initiatives (simple, doable, meaningful, realistic) that can effectively bring FESEO into the Spanish oncology landscape as THE true platform for multidisciplinary oncology. Three distinct and doable initiatives have already been proposed:

(1) A guide for cancer in the adolescent, a project promoted by SEHOP (currently in partnership with SEOM) that could easily become the "FESEO Multidisciplinary Guide for Cancer in the Adolescent”) if we get all member societies involved in its elaboration.

(2) At least one press release in a year by FESEO, with consensus by all member societies, in the event of a milestone on cancer care or cancer research, thus avoiding (for us and for the public) a bombardment by multiple individual press releases on a same crucial issue.

(3) The value of the FESEO stamp as a sign of multidisciplinarity in the contents of any Oncology educational or scientific event was reassessed and revamped. A clear FESEO auspice/endorsement policy was discussed and agreed unanimously on, being already in effect.

Furthermore, if FESEO is to carry our progressively more actions as a true federation of scientific societies and not a mere journal manager, it needs to become a little bit more professional in its management. Therefore, the FESEO Board agreed to incorporate the figure of a Chief Operating Officer (COO); somebody dependable and trustworthy, who shares the identity and spirit of FESEO, who has a historic vision into the federation and who is proficient in general management issues and specifically in the Oncology Spanish context. Our Board of Directors unanimously agreed to offer this position to Marisol Moreno, recognizing the hard and diligent work carried out over many years as Head Editor of CTO in very adverse professional and contractual conditions. She accepted, and subsequently Marisol has been appointed COO of FESEO, effective immediately. This Board heartfelt congratulates her for this well-deserved new achievement in her career (Fig. 1). 
Fig. 1 Attendants to the 106 FESEO Board of Directors Meeting (27 February, 2018). Sitting, left to right: Pere Gascón. (Editor in Chief. Clinical \& Translational Oncology), Jesús $\mathrm{M}^{\mathrm{a}}$ Paramio (ASEICA), Ana Fernández-Teijeiro (SEHOP), Jose Ignacio Chacón (SEOM). Standing, left to right: Jacobo Cabañas (SEOQ), Maria Sol Moreno (Editorial Manager. Clinical \& Translational Oncology), Santiago GonzálezMoreno (SEOQ), Carlos J. Ferrer (SEOR), Encarna GonzálezFlores (SEOM)

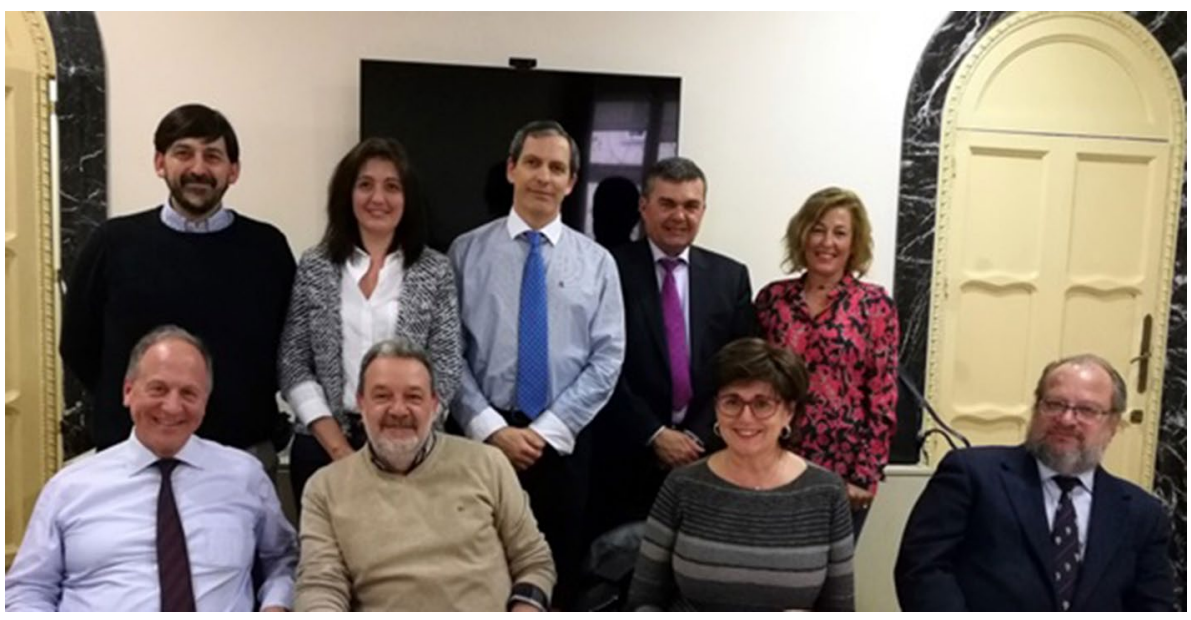

\section{Conclusion}

It is possible that beyond amazing technical and medical advances, the advent of multidisciplinary cancer care that integrates them all should be considered as THE revolution in cancer management that evolved over the last quarter of the past century and is here to stay. If we fail to honor this principle we will be ignoring the very biological nature of the disease we treat and claim expertise in. And we will fail in our ultimate goal to eradicate or at least have cancer under our control one day. We call all stakeholders in Oncology including patient organizations, governmental agencies and scientific societies, to give small but meaningful steps towards a REAL MULTIDISCIPLINARITY in cancer care and research in Spain and in Europe. It will be the breakthrough that our patients will benefit most from. And we are convinced we CAN make it happen.

Santiago González-Moreno, MD, PhD

President of FESEO (2017-2018)

Past-President of SEOQ (2017-2019)

On behalf of the FESEO Board of Directors (2017-2018)*

* FESEO Board of Directors 2017-2018 is composed of:

President: Santiago González-Moreno (SEOQ)

Vice President: Pedro Carlos Lara (SEOR)

Secretary: Jesús Ma Paramio (ASEICA)

Treasurer: Encarna González-Flores (SEOM)

Board Members:

Ruth Vera (SEOM)

Jose Ignacio Chacón (SEOM)

A. Rodríguez-Lescure (SEOM)

Carlos Camps (ASEICA)

Carlos J. Ferrer (SEOR)

Ana Fernández-Teijeiro (SEHOP)

Jacobo Cabañas (SEOQ)
Acknowledgements FESEO Board of Directors are: President: Santiago González-Moreno (SEOQ), Vice President: Pedro Carlos Lara (SEOR), Secretary: Jesús Ma Paramio (ASEICA), Treasurer: Encarna González-Flores (SEOM), Board Members: Ruth Vera (SEOM), Jose Ignacio Chacón (SEOM), A. Rodríguez-Lescure (SEOM), Carlos Camps (ASEICA), Carlos J. Ferrer (SEOR), Ana Fernández-Teijeiro (SEHOP), Jacobo Cabañas (SEOQ).

\section{Compliance with ethical standards}

Conflict of interest The author declares that he has no conlict of interest. 